\title{
ALCOHOL CONSUMPTION AND ALCOHOL ADVERTISING BANS
}

\author{
Henry Saffer \\ Working Paper 7758 \\ http://www.nber.org/papers/w7758
}

\section{NATIONAL BUREAU OF ECONOMIC RESEARCH 1050 Massachusetts Avenue Cambridge, MA 02138 \\ June 2000}

This project was supported by Grant Number R01 AA09867 from the National Institute on Alcohol Abuse and Alcoholism to the National Bureau of Economic Research. Thanks to Dhaval Dave for programming assistance and helpful comments. The views expressed herein are those of the author and not necessarily those of the National Bureau of Economic Research.

(C) 2000 by Henry Saffer. All rights reserved. Short sections of text, not to exceed two paragraphs, may be quoted without explicit permission provided that full credit, including (C) notice, is given to the source. 
Alcohol Consumption and Alcohol Advertising Bans

Henry Saffer

NBER Working Paper No. 7758

June 2000

JEL No. I1

\begin{abstract}
The purpose of this paper is to empirically examine the relationship between alcohol advertising bans and alcohol consumption. Most prior studies have found no effect of advertising on total alcohol consumption. A simple economic model is provided which explains these prior results. The data set used in this study is a pooled time series of data from 20 countries over 26 years. The empirical model is a simultaneous equations system which treats both alcohol consumption and alcohol advertising bans as endogenous. The primary conclusions of this study are that alcohol advertising bans decrease alcohol consumption and that alcohol consumption has a positive effect on the legislation of advertising bans. The results indicate that an increase of one ban could reduce alcohol consumption by five to eight percent. The alcohol price elasticity is estimated at about .2. The results suggest that recent exogenous decreases in alcohol consumption will decrease the probability of enactment of new bans and undermine the continuance of existing bans. Canada, Denmark, New Zealand and Finland have recently rescinded alcohol advertising bans. Alcohol consumption in these countries may increase or decrease at a slower rate than would have occurred had advertising bans remained in place.
\end{abstract}

Henry Saffer

National Bureau of Economic Research

365 Fifth Avenue, $5^{\text {th }}$ floor

New York, NY 10016-4309

hsaffer@gc.cuny.edu 


\section{Introduction}

Data from a number of countries indicate that both the level of alcohol related problems and the level of alcohol advertising are substantial. For example, Lehto (1995) reports that in Europe, six percent of all mortality among people under 75 , and 20 percent of all acute hospital admissions are related to alcohol use. Data from Advertising Age (1999) show that in 1998 five alcohol companies ranked in the top 100 advertisers worldwide. Also, Competitive Media Reporting (1999) estimates that in the US, alcohol advertising exceeded $\$ 1.2$ billion in 1998 , with three brewers ranking among the top 100 advertisers in the US.

The appropriateness of alcohol advertising has been publicly debated for some time. The central issue in these discussions is whether advertising affects total alcohol consumption or whether its effects are limited to brand choice. Although media portrayals of alcohol generally reflect social conventions about alcohol, some public health advocates claim that these large expenditures may also affect social conventions and increase alcohol abuse. The alcohol industry claims that alcohol advertising only affects brand choice. The issue of continuing or eliminating restrictions on alcohol advertising has been repeatedly scrutinized at the highest levels of government. In the US, the Surgeon General and various congressional committees have questioned the continued use of broadcast advertising by the beer and wine industries. However, the introduction of spirits advertising on cable TV, in 1996, was not opposed. In France, in 1993 stringent new limits on alcohol advertising were enacted. These new limits have been supported by the Directorate General of the EC as consistent with the single market of the European Union. Alternatively, in 1992, New Zealand, and in 1995, Finland, Denmark and Canada eliminated bans on alcohol advertising. 
The purpose of this paper is to empirically examine the relationship between alcohol advertising bans and alcohol consumption. The focus on advertising bans is important because bans are a likely choice of public policy for the control of alcohol advertising. The data set used in this study is a pooled time series of data from 20 countries over 26 years. Farley and Lehmann (1994) find that cross-national differences in the response to advertising are relatively small. The use of international data is an effective method for measuring the effect of a ban on alcohol advertising. Data from one country are not as useful since changes in alcohol advertising bans within countries are rare and the imposition of a ban may require an extended period for consumption to adjust. There is, however, considerable variation in the use of advertising bans across countries.

\section{Prior Studies}

Over the past 25 years, there have been a number of econometric studies which have examined the effects of alcohol advertising on total alcohol consumption. These studies have measured the effect of advertising expenditures and advertising bans. Most of these studies used aggregated national expenditures as the advertising variable and have provided little evidence that alcohol advertising increases alcohol consumption. However, studies that have used cross sectional advertising data and studies of alcohol advertising bans have found effects on alcohol consumption.

These seemingly contradictory results can be explained by a simple economic model of advertising. This model is based on the assumption that the industry level advertising response function is subject to diminishing marginal product. An advertising response function relates consumption or sales revenue to advertising messages or expenditures. Advertising response functions are generally studied at the firm level since almost all advertising is done at the firm level (i.e. Rao and Miller 1975, Stewart 1989, Lodish et al. 
1995). The consensus of firm level research is that advertising increases sales and that these increases are subject to diminishing marginal product. Firm level advertising response functions hold constant all other determinants of firm level sales including advertising by rivals and product price. For the firm, new sales induced by advertising come from two sources. First, new sales come from consumers who would have purchased from rival firms, i.e. increasing market share. Second, new sales come from consumers who would not have purchased the product at all or who purchased less of the product, i.e. increasing the market size. An industry level response function is derived by aggregating the firm level response functions. At the industry level, advertising can increase sales only by increasing market size.

The industry advertising response function is illustrated in Figure 1 and assumes that the advertising of all the firms in the industry increases industry level sales and that the increases are subject to diminishing marginal product. The industry advertising response function holds constant all other determinants of industry level sales including advertising by other industries and industry price. The results from prior econometric studies of alcohol advertising are consistent with the industry level advertising response function. These studies can be classified by the definition of the advertising variable into three categories. The first category includes studies which measure advertising with annual national data. Highly aggregated measures such as annual national data have two problems. First, since alcohol is among the most heavily advertised consumer goods, it is likely that highly aggregated advertising data are in the range of zero marginal product. The range of zero marginal product corresponds to a range around $\mathrm{A}_{1}$ in figure 1. Second, this level of aggregation eliminates the variance in advertising needed to find any correlation with consumption. Empirical studies which use annual national alcohol advertising as an independent variable are thus not likely to find that advertising has any relationship to consumption. The studies of this type reported in table 1 generally find no effect of alcohol advertising. 
The second category includes studies which use cross sectional data as the measure of alcohol advertising. This type of data would typically be local level, such as a Metropolitan Statistical Area, for periods of less than a year. Local level data can have greater variation than national level data for several reasons. One reason for the variation in this type of data is pulsing. ${ }^{1}$ The pattern of these pulses varies over local areas. Another reason for variation in advertising levels is that the cost of advertising varies across local areas. This is illustrated in Figure la by the three data points $\mathrm{Am}_{1}, \mathrm{Am}_{2}$ and $\mathrm{Am}_{3}$. An econometric study which uses monthly or quarterly local level data would have potentially larger variation in advertising levels and in consumption. When the data are measured over a relatively larger range, there is a greater probability of being in an upward sloping portion of the response function. Local level advertising data are thus more likely to find a positive relationship between advertising and consumption. The two studies of this type listed in Table 1 find evidence that alcohol advertising has a positive and significant effect on consumption.

The third category includes studies of advertising bans on consumption. The potential effect of a ban on certain media is shown as a downward shift of the response function in Figure 1. An advertising ban may not reduce the total level of advertising but will reduce the effectiveness of the remaining non-banned media. The reason for this is that a ban on the use of a specific media will result in substitution to the remaining non-banned media. However, each media is subject to diminishing marginal product. The increased use of the non-banned media will result in a lower average product for these media. This shifts the response function downward. Firms may or may not respond to this decrease in effectiveness of their advertising expenditures. Firms may try to compensate with more advertising which would be illustrated by

\footnotetext{
${ }^{1}$ Pulsing refers to the common practice of advertising in short intense bursts of spending. This practice maximizes the value of the lingering effects of advertising.
} 
moving to a higher level of advertising on a lower advertising response function. ${ }^{2}$ Firms might also increase the use of other marketing techniques such as promotional allowances to retailers. The effects of advertising bans have been studied with interrupted time series techniques and in regression models.

Studies of alcohol advertising bans using interrupted time series techniques listed in Table 1 found that advertising bans had no effect on alcohol consumption. However, interrupted time series cannot account for other factors such as cross-border alcohol advertising coming from the US. These results may also indicate that in a single province or country study, a long time period is necessary before there is any observable change in alcohol consumption. These provincial bans may not have resulted in much of a reduction in total advertising exposure since these provinces receive a considerable amount of television programming from the US.

The two prior ban studies listed in Table 1 which are most relevant for this paper are Saffer (1991) and Young (1993). Saffer (1991) examines the effect of banning broadcast advertising of alcoholic beverages on alcohol abuse. The data used in this study are a pooled time series from 17 countries for the period 1970 to 1990 . The empirical results show that alcohol advertising bans have a significant effect in reducing alcohol consumption. Young (1993), in an alcohol industry supported study, comments on Saffer (1991). Young undertakes the re-analysis of the data used in Saffer (1991) and is successful in recreating the results found in Saffer (1991). Two points raised by Young (1993) are the potential for serial correlation and the problem of endogeneity of advertising bans. As described in Saffer (1993), Young fails to correctly apply the serial correction procedure. Young also fails to provide any correction for endogeneity bias. The analysis presented below seeks to address these problems.

\footnotetext{
${ }^{2}$ In a simple model, the decrease in marginal product would reduce the use of the input. However in an oligopoly model, with response to rivals, one reaction to reduced sales is to increase advertising.
} 


\section{Empirical Framework}

Endogeneity between advertising bans and consumption is possible since the level of consumption and associated social ills may be factors in precipitating new bans. Falling alcohol consumption might also undermine the continuance of existing bans. This problem is addressed with a two equation structural model estimated with TSLS. Also, due to the time series nature of the data set serial correlation might be present. Serial correlation can be addressed with Huber standard errors.

The first structural equation is an alcohol demand function which relates price, income and other variables to alcohol consumption. The demand function for alcohol can be represented as:

$\mathrm{A}=\mathrm{A}\left(\mathrm{P}_{\mathrm{A}}, \mathrm{Z}, \mathrm{B}\right)$

Demand theory predicts that the price of alcohol $\left(\mathrm{P}_{\mathrm{A}}\right)$ will have a negative effect on alcohol consumption.

Other factors $(\mathrm{Z})$ such as income and culture will also affect alcohol consumption. Alcohol advertising bans (B) enter the demand curve as a measure of alcohol advertising. If advertising increases consumption, and if a set of bans on certain media reduces total advertising, then advertising bans will have a negative effect on alcohol consumption.

The second structural equation assumes that the legislation of alcohol advertising bans is a function of public attitudes about alcohol. This equation is based on the theory of public choice as defined by Deacon and Shapiro (1975) and Saffer and Grossman (1987). The theory suggests that the legislation of alcohol advertising bans reflects public attitudes towards alcohol related problems:

$\mathrm{B}=\mathrm{B}(\mathrm{A}, \mathrm{X}, \mathrm{E})$

Public attitudes can be affected by the level of excessive alcohol consumption, highway fatality rates, liver cirrhosis mortality and other social dysfunctions resulting from alcohol abuse. These problems have been found to correlate with alcohol consumption (A). Exogenous attitudes (X), including attitudes towards 
government in the economy, attitudes towards government in the health sector, attitudes towards alcohol in social custom, and attitudes towards restricting advertising, can also affect the passage of alcohol advertising bans. The economic importance of alcohol (E), resulting from alcohol production related employment and income, can also affect attitudes toward the passage of alcohol advertising bans.

The data set used in this study is a time series of cross sections consisting of 20 countries for the years 1970 through 1995. An international data set provides more changes in ban status than a single country data set. An international data set also provides time variation which is not available in an individual level cross sectional data set. The 20 countries included in the data set are all members of the OECD. The OECD countries were chosen because they have attempted to maintain a data base of comparable economic and social data since 1960. The data set was limited to 20 countries since four OECD countries do not report the necessary data. Table 2 contains summary definitions and mean values for all the variables.

The dependent variable used in the alcohol regressions is the natural logarithm of per capita annual consumption of pure alcohol in liters. The variable is computed by adding together the per capita consumption of pure alcohol in beer, wine and spirits and then taking the natural logarithm of the sum. These data come from the Brewers Association of Canada (BAC, various years).

The second dependent variable measures the number of alcohol advertising bans enacted in each country. All advertising ban legislation group beer and wine into one category with spirits treated as a separate category. This generality applies to all countries included in this study. ${ }^{3}$ Some countries have restrictions on the times that alcohol advertising can be broadcast or on the content of the advertisements.

\footnotetext{
${ }^{3}$ The beer and wine category includes all alcoholic beverages with 23 percent or less alcohol (with the exception of light beer in Scandinavia which is exempt from advertising bans). Spirits is everything above 23 percent. Advertising bans include both voluntary and mandatory prohibition of all advertisements by alcohol beverage category.
} 
In defining the ban variables, these limited restrictions have been coded as zero. The reason for this is that the advertising industry has demonstrated skill in circumventing limited restrictions. There is no evidence that limited restrictions have any impact on the level of advertising. In defining the advertising bans, if only spirits are banned in a media, then the ban is defined as partial, and if all alcohol advertising is banned in a media, then the ban is considered total. The first alcohol advertising ban is defined as the number of partial alcohol advertising bans. This ban variable counts the number of advertising bans on beer and wine or on spirits, by media. Since there are three media included, and two beverage groups, this variable can take on values from zero to six. In defining this variable, if a country bans both spirits advertising and beer and wine advertising, in a media, then this would be counted as two bans. The second alcohol advertising ban is defined as a total ban since it measures the number of media that ban spirits and ban beer and wine advertising. The ban data come primarily from the BAC (various years).

The alcohol price variable was computed by dividing private final alcohol expenditures by pure alcohol consumption in liters. ${ }^{4}$ The data were divided by the gross domestic product deflator using 1985 as the base year. The data were converted to United States dollars by dividing by the purchasing power parity. $^{5}$ Alcohol expenditures, the deflator and purchasing power parities were taken from the

\footnotetext{
${ }^{4}$ The price of alcohol is assumed to be exogenous. This assumption is based on the competitive international market in alcoholic beverages which creates a very elastic supply function. This leaves the variation in price across countries largely the result of variation in taxes. Taxes could be endogenous, but are a relatively limited percent of the price. This price variable has two problems. First, the price variable may be correlated with the equation error term if alcohol consumption is measured with error. Second, changes in the percentages of alcohol consumed in the form of beer, wine and spirits will result in changes in the price variable even when the underlying beverage prices are constant.

${ }^{5}$ Price and income are reported in units of national currency and must be standardized using purchasing power parities. The OECD reports purchasing power parities for the member countries based on 1980 survey data. Although reliability diminishes with distance from the sample year, purchasing power parities can be estimated for earlier years using inflation rates. The first year of the data set used in this study is 1970 since 1970 is as far back as the OECD estimates purchasing power parities.
} 
Organization for Economic Cooperation and Development (OECD) National Accounts (various years).

Alcohol consumption data come from the BAC (various years).

Real income was computed by first dividing gross domestic product by population. This was then divided by the gross domestic product deflator and the purchasing power parity. The data are in thousands of US dollars and come from the OECD National Accounts (various years).

The economic value of alcohol production can affect the passage of legislation which might reduce alcohol consumption. A reduction in alcohol consumption would cause economic harm to those who derive their incomes from alcohol production. To account for this, the annual production of beer and the annual production of wine is included in the data set. Both variables are measured in hectoliters and are divided by population. The beer production data come mostly from the UN Industrial Commodity $\underline{\text { Statistics Yearbooks (various years) and the wine production data come mostly from FAO Production }}$ $\underline{\text { Yearbooks (various years). }}{ }^{6}$

Several measures of public attitudes towards intervention to promote public health are included in the ban demand equation. The number of media from which cigarette advertising is banned is included in the data set. Cigarette advertising bans are included since the public attitudes which are causal in the legislation of cigarette advertising bans may also influence the legislation of alcohol advertising bans. ${ }^{7}$ The cigarette advertising ban data come from Health New Zealand (1995) and World Health Organization (1997). Another measure of public attitudes is the percentage of total health spending that is paid for by government. These data come from the OECD Health Data, 1998. Finally, the percentage of GDP which

\footnotetext{
${ }^{6}$ Spirits production was not included because there were too many missing values.

${ }^{7}$ Since the legislation of cigarette advertising bans could also be a function of alcohol advertising bans, the cigarette ban variable could be correlated with the error term in the alcohol advertising ban equation.
} 
is spent by the government is included as a measure of attitudes towards government intervention. These data also come from OECD Health Data, 1998.

The data set includes a complete set of country and time dummy variables. The country dummy variables are included as a control for all unobserved time invariant country specific factors which affect alcohol consumption and the legislation of alcohol advertising bans. Similarly, the time dummy variables are included as a control for country invariant time specific changes in alcohol consumption and alcohol advertising bans.

The country dummy variables are important in an international data set due to the limited availability of country specific control variables. However, since the advertising ban variables have limited time variation, the inclusion of country dummy variables in the alcohol consumption structural model creates colinearity with these ban variables. One solution to this problem is the use of an alcohol culture variable in place of the country dummy variables in the alcohol consumption equation. The country dummy variables can still be retained in the advertising ban equation and therefore also retained in both reduced form equations.

According to a review of several studies by the BAC (1997), the alcohol culture of a country can be defined by the intended outcome of consumption. Alcohol consumed with meals, or during traditional events, family and community gatherings and other social gatherings is generally not intended to result in intoxication but rather to enhance the social aspect of these situations. Beer and wine tend to be the alcoholic beverage choice for these situations. Alcohol is also consumed in circumstances, social or otherwise, where the intention is intoxication. Spirits tend to be the beverage choice when intoxication is primarily the intended outcome. Countries vary with respect to the intention of alcohol use. The alcohol culture variable is defined as the percent of total alcohol which is consumed in the form of beer and wine. 
Countries with larger values for this variable consume a greater percent of alcohol in the form of beer and wine and, given the above assumptions, are more likely to consume alcohol as an enhancement to traditional life rather than for intoxication. This variable also has time variation, since over time spirits have lost market share to beer and wine.

\section{The Regression Results}

Before proceeding to the estimation it is important to examine the data for serial correlation. A Durbin Watson test for each country time series resulted in an average value of .71 which indicates possible serial correlation. Huber standard errors, using country as the cluster variable, were estimated for all coefficients to correct for serial correlation.

Another important econometric issue is to test the assumption of endogeneity between alcohol advertising bans and alcohol consumption. Wu-Hausman endogeneity tests were performed for both the partial and total ban variables and for models which both include and exclude the country dummy variables from the structural alcohol consumption equation. ${ }^{8}$ The Wu-Hausman tests indicate that bans are endogenous in the alcohol consumption structural equations with country dummies excluded. These tests do not indicate endogeneity of alcohol consumption in the ban equations. However, when the advertising ban equations are estimated as OLS equations, alcohol consumption has a significant positive effect. These results, taken together, provide enough evidence to conclude that the two variables are endogenous.

\footnotetext{
${ }^{8}$ These tests were performed by predicting the potentially endogenous variable with the reduced form equation and then including the predicted value along with the actual value in the structural equation. A statistically significant coefficient, at the 10 percent level, for the predicted endogenous variable is considered evidence of endogeneity.
} 
Another econometric concern is the normality of the ban variables. Inspection of the ban data reveals both ban variables are equal to zero for over 40 percent of the sample. That is, for a number of countries, or time periods within countries, there were no alcohol advertising bans at all. The large number of zeros makes the ban variable non-normal which can affect the standard errors in the equations which use the ban as the dependent variable. The negative binomial procedure can be used for estimation when the dependent variable has a large number of zeros. To judge the severity of this problem, negative binomial estimates and OLS estimates of the ban equations, assuming exogeneity of alcohol consumption were compared. Negative binomial estimates were substantially the same as the OLS estimates. Therefore, the non-normality of the ban variable does not appear to be an important problem.

Table 3 presents results for TSLS estimates of the structural model. The first three regressions employ the partial advertising ban variable. Equation 1 shows that, at the 10 percent level, partial alcohol advertising bans reduce alcohol consumption. This equation excludes country dummy variables but includes the alcohol culture variable, which is significant. ${ }^{9}$ Alcohol price is negative and significant. The price elasticity is estimated at .19, which is somewhat lower than other studies. Income has a positive effect on alcohol consumption, which has also been found in other studies. In equation 2 , the country dummy variables are included. The alcohol culture variable becomes insignificant as does the partial advertising ban variable, since these variables are collinear with the country dummy variables. Alcohol price and income remain significant. Equation 3 is the partial advertising ban equation. The only significant variable is government spending as a share of GDP. The implication from equation 3 is that alcohol consumption does not affect the number of partial bans.

\footnotetext{
${ }^{9}$ The country dummy variables are included in both reduced form equations and in the advertising ban equations.
} 
Table 3 also presents results for TSLS estimates of the structural model with the total advertising ban variable. Equation 4 is similar to equation 1. Again, at the 10 percent level, total bans reduce alcohol consumption. Alcohol price is again negative and significant while income is again positive and significant as is alcohol culture. Equation 5 is also similar to equation 2. The alcohol culture variable becomes insignificant as does the advertising ban variable due to colinearity with the country dummy variables. Equation 6, however, is different from equation 3. Alcohol consumption is found to have a significant positive effect on total advertising bans. ${ }^{10}$ This suggests that higher alcohol consumption will result in more total advertising bans. In equation 6 , the alcohol culture variable, cigarette advertising bans and government spending are also positive and significant. These results suggest that more total bans will be enacted in countries were the alcohol culture is more social, where there are more cigarette advertising bans and where government is more involved in the economy.

\section{Conclusions}

The primary conclusion of this study is that alcohol advertising bans decrease alcohol consumption. The effect of bans may increase as the number of bans increases due to non-linearities in the relationship between bans and consumption. Although there have been many econometric studies of alcohol advertising policy, there are few prior studies of the effect of advertising bans on alcohol consumption. Advertising bans are, however, a likely choice of public policy for the control of alcohol advertising. One prior study of advertising bans is Saffer (1991). The present study updates Saffer (1991) by adding additional years and countries and by correcting for serial correlation and endogeneity of

\footnotetext{
${ }^{10}$ An alternative set of regressions which excluded the beer and wine production variables was also estimated since these variables have missing data for over 60 observations. The results were substantially the same as those reported in
} 
advertising bans. The results from Saffer (1991) suggested that an added advertising ban could reduce alcohol consumption by about five to eight percent. The results in this study are very similar to Saffer (1991). These results indicate that one more ban on beer and wine or on spirits would reduce consumption by about five percent and one more ban on all alcohol advertising in a media would reduce consumption by about eight percent.

There is also evidence that alcohol consumption has a positive effect on total advertising bans. That is, an increase in alcohol consumption can increase the probability of legislation of an advertising ban on all forms of alcohol in a particular media. However, alcohol consumption has been trending downward in a number of countries since around 1988. These decreases may reflect changes in exogenous factors such as increases in the demand for health. This downward trend in alcohol consumption could result in a decrease in the number of advertising bans. Canada, Denmark, New Zealand and Finland recently decreased the number of total advertising bans in effect. These decreases maybe examples of the difficulty in maintaining alcohol advertising restrictions when alcohol consumption is on a downward trend. Alcohol consumption in these countries may increase or decrease at a slower rate than would have occurred had the advertising bans remained in place. the 11.5 percent level for a two-tailed test. 


\section{References}

Advertising Age, Dataplace, www.adage.com, 1999.

Blake, D. and A. Nied, "The Demand for Alcohol in the United Kingdom", Applied Economics, 29, 16551672, 1997.

Bourgeois, J. and J. Barnes, "Does Advertising Increase Alcohol Consumption?", Journal of Advertising

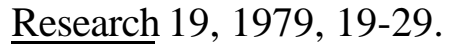

Brewers Association of Canada, International Survey of Alcohol Beverage Taxation and Control Policies published by the Brewers Association of Canada, various years.

Calfee, J. and C. Scheraga, "The Influence of Advertising on Alcohol Consumption: A Literature Review and An Econometric Analysis of Four European Nations," International Journal of Advertising, vol. 13, no. 4, 1994. p. 287-310.

Competitive Media Reporting, LNA/Media Watch Multi-Media Service, CMR, New York, 1999.

Deacon, R. and P. Shapiro, "Private Preferences for Collective Goods revealed Through Voting on Referenda," American Economic Review, 943-955, vol. 65, no. 5, 1997

Duffy, M., "Advertising and the Inter-product Distribution of Demand", European Economic Review, 31, 1987, 1051-1070.

Duffy, M. "Advertising in Demand Systems: Testing a Galbraithian Hypothesis", Applied Economics, 23, 1991, 485-496.

Duffy, M., "Advertising in Demand Systems for Alcoholic Drinks and Tobacco: A Comparative Study," Journal of Policy Modeling, vol. 17 no. 6, p. 557-577, 1995.

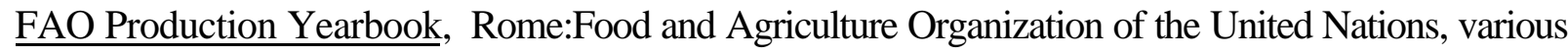
years.

Farley JU, Lehmann DR. Cross-national "laws" and differences in market response. Management Science 1994;40(1):112-122.

Franke, G. and G. Wilcox, "Alcoholic Beverage Advertising and Consumption in the United States, 19641984", Journal of Advertising, 16, 1987, 22-30.

Goel, R., and M. Morey, "The Interdependence of Cigarette and Liquor Demand," Southern Economic Journal, vol. 62, no. 2, p. 441-459, 1995. 
Grabowski HG. The effect of advertising on the inter-industry distribution of demand. Explorations in Economic Research 1976;3:21-75.

Health New Zealand. Tobacco Use among the OECD Industrialized Countries since 1960: Advertising Restrictions \& Health Warnings. New Zealand: Health New Zealand, 1995.

Heien, D. and G. Pompelli, "The Demand for Alcoholic Beverages: Economic and Demographic Effects," Southern Economic Journal, vol. 55, no. 3, Jan., 1989.

Lehto J. Approaches to Alcohol Policy, WHO Regional Publications, European Series, no 601995.

Lodish, L.M., et al., 1995, How tv advertising works: a meta-analysis of 389 real world split cable tv advertising experiments, Journal of Marketing Research 32, 125-139.

Makowsky, C., and P. Whitehead, "Advertising and Alcohol Sales: A Legal Impact Study," Journal of Studies on Alcohol, vol. 52, no. 6, 1991. p. 555-566.

McGuiness, T. "An Econometric Analysis of Total Demand for Alcoholic Beverages in the U.K. 19651975", Journal of Industrial Economics, 29, 85-105, 1980.

McGuiness, T. "The Demand for Beer, Spirits and Wine in the UK, 1956-1979", in Grant, Plant and Williams, eds. Economics and Alcohol Gardner Press, Inc. New York. 1983, 238-242.

Nelson J. and J. Moran, “Advertising and US Alcoholic Beverage Demand: System-Wide Estimates”, Applied Economics, 27:123-131, 1995.

Nelson J. Broadcast Advertising and US Demand for Alcoholic Beverages", $\underline{\text { Southern Economic Journal }}$ 65(4) 774-790, 1999.

Organization for Economic Cooperation and Development, Health Data 1997, Geneva Switzerland, 1998.

Switzerland, various years. National Accounts Volume I and II, Geneva,

Ogborne, A., and Smart, R., Will Restrictions on Alcohol Advertising Reduce Alcohol Consumption?," British Journal of Addiction, 75, 293-296 1980.

Ornstein, S. and Hanssens, D., "Alcohol Control Laws and the Consumption of Distilled Spirits and Beer", Journal of Consumer Research, 12, 200-213, 1985.

Rao, R. and P. Miller, “Advertising/Sales Response Functions”, Journal of Advertising Research, 15:7-15, 1975. 
Saffer, H. and Grossman, M. "Drinking Age Laws and Highway Mortality Rates: Cause and Effect", Economic Inquiry, vol. XXV, 1987, 403-417.

Saffer, H., "Alcohol Advertising Bans and Alcohol Abuse: An International Perspective", Journal of Health Economics, 10., 65-79, 1991.

Saffer, H. "Alcohol Advertising Bans and Alcohol Abuse: Reply", Journal of Health Economics, 12., 229234, 1993.

Saffer, H. "Alcohol Advertising and Alcohol Consumption: Econometric Studies," in The Effects of the Mass Media on the Use and Abuse of Alcohol, S. Martin and P. Mail, eds., Rockville MD: National Institute on Alcohol Abuse and Alcoholism, 1995.

Saffer, H. "Studying the Effects of Alcohol Advertising on Consumption," Alcohol Health and Research World, NIAAA, vol. 20, no. 4, 1996.

Saffer, H. "Alcohol Advertising and Highway Fatalities," Review of Economics and Statistics, vol. 79, no. 3, August, 1997.

Saffer, H. "Economic Issues in Cigarette and Alcohol Advertising", Journal of Drug Issues, vol. 28, no.3 summer 1998.

Saffer, H. and F. Chaloupka, "The Effect of Tobacco Advertising Bans on Tobacco Consumption", Journal of Health Economics, forthcoming.

Selvanathan, E., "Advertising and Alcohol Demand in the UK: Further Results", International Journal of Advertising, 8, 1989, 181-188.

Smart, R. and Cutler R., "The Alcohol Advertising Ban in British Columbia: Problems and Effects on Beverage Consumption,” British Journal of Addiction, 71, 13-21 1976.

Stewart, D. "Measures, Methods, and Models in Advertising Research", Journal of Advertising Research, 54-60, June/July 1989.

United Nations, Industrial Commodity Statistics Yearbook, New York, various editions.

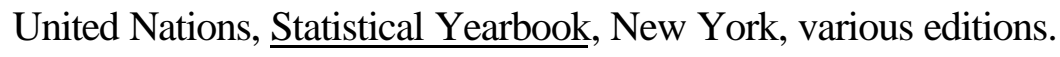

World Health Organization, “Tobacco or health:A global status report”, WHO: Geneva, 1997.

Young, D. (1993), "Alcohol Advertising Bans and Alcohol Abuse: Comment ", Journal of Health Economics, 12., 213-228, 1993. 


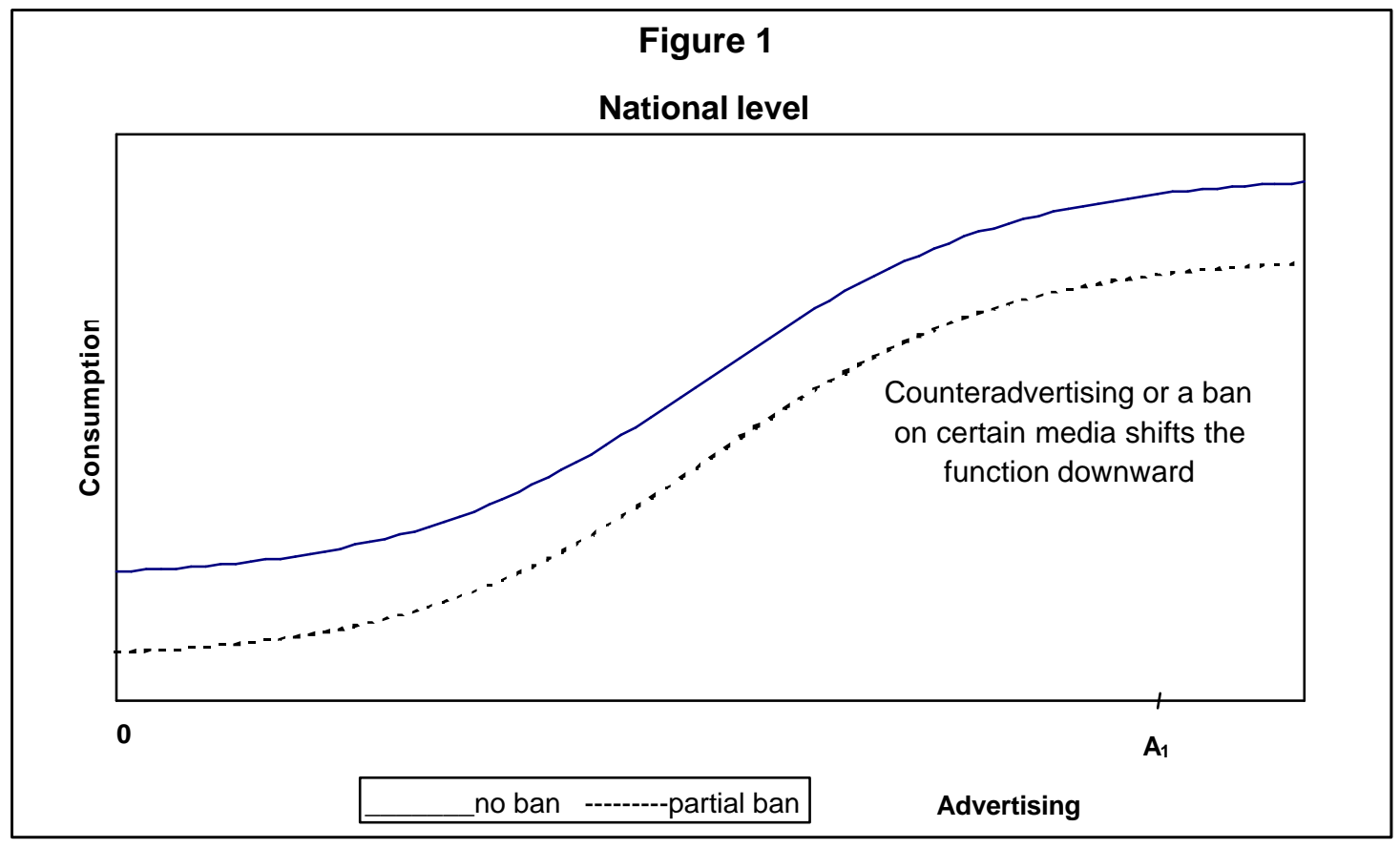

Figure 1a

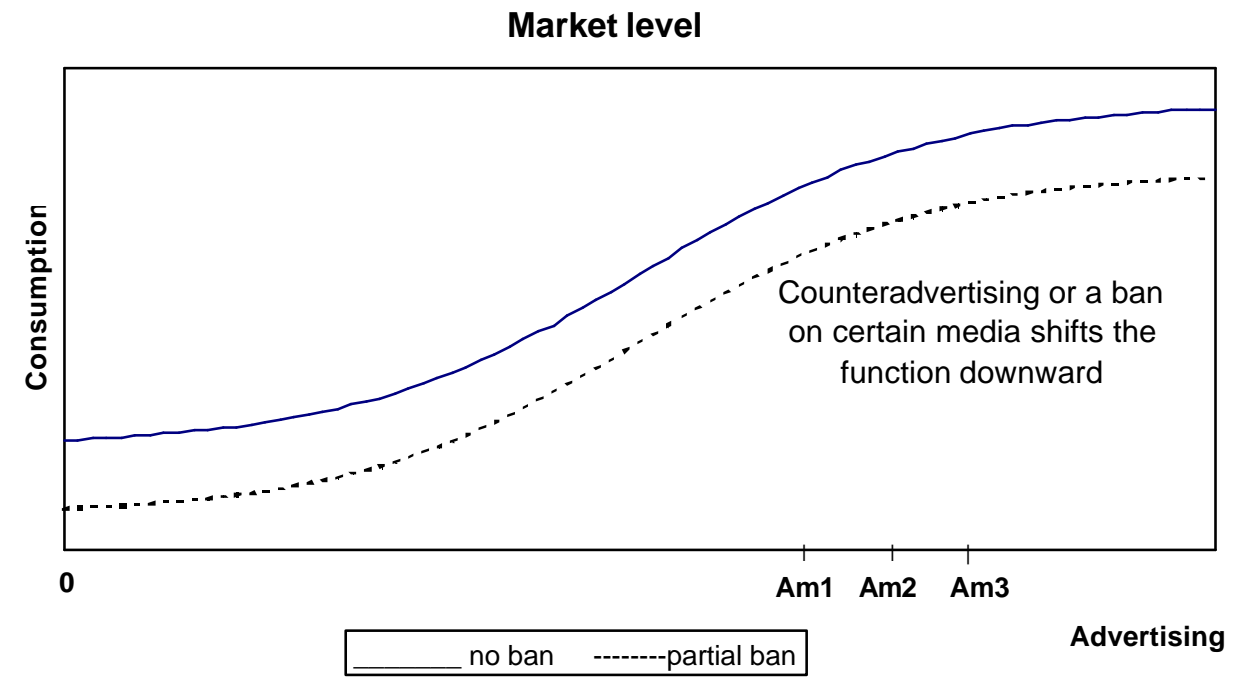




\section{Table 1}

\section{Prior Empirical Studies*}

\begin{tabular}{|c|c|c|}
\hline STUDY & DATA & CONCLUSION \\
\hline \multicolumn{3}{|l|}{ TIME SERIES STUDIES } \\
\hline Blake and Nied (1997) & UK 1952-1991 & small positive effect of advertising \\
\hline Bourgeois and Barnes (1979) & Canada 1951-1974 & no effect of advertising \\
\hline Calfee and Scheraga (1994) & $\begin{array}{l}\text { France Germany, } \\
\text { Netherlands Sweden }\end{array}$ & no effect of advertising \\
\hline Duffy (1987) & UK 1963-1983 & no effect of advertising \\
\hline Duffy (1991) & UK1963-1985 quarterly & no effect of advertising \\
\hline Duffy (1995) & UK1963-1988 quarterly & no effect of advertising \\
\hline Franke and Wilcox (1987) & US 1964-1984 quarterly & $\begin{array}{l}\text { small positive effect of beer and wine } \\
\text { advertising }\end{array}$ \\
\hline Grabowski (1976) & US 1956-1972 & no effect of advertising \\
\hline McGuiness (1980) & UK 1956-1975 & $\begin{array}{l}\text { small positive effect of spirits } \\
\text { advertising }\end{array}$ \\
\hline McGuiness (1983) & UK 1956-1979 & small positive effect of beer advertising \\
\hline Nelson (1999) & US quarterly & no effect of advertising \\
\hline Nelson and Moran (1995) & US 1964-1990 & no effect of advertising \\
\hline Selvanathan (1989) & UK 1955-1975 & small positive effect of beer advertising \\
\hline \multicolumn{3}{|l|}{$\begin{array}{c}\text { CROSS-SECTIONAL } \\
\text { STUDIES }\end{array}$} \\
\hline Goel and Morey (1995) & US 1959-1982 & positive effect of advertising \\
\hline Saffer (1997) & US 1986-1989 quarterly & positive effect of advertising \\
\hline \multicolumn{3}{|l|}{ BAN STUDIES } \\
\hline \multicolumn{3}{|l|}{ Interrupted Time Series } \\
\hline $\begin{array}{l}\text { Makowsky and Whitehead } \\
\text { (1991) }\end{array}$ & Saskatchewan & no effect of advertising \\
\hline Ogborne and Smart (1980) & Manitoba & no effect of advertising \\
\hline Smart and Cutler (1976), & British Columbia, & no effect of advertising \\
\hline \multicolumn{3}{|l|}{ Multivariate } \\
\hline Ornstein and Hanssens (1985) & US 1974-1978 & positive effect of price advertising \\
\hline Saffer (1991) & OECD 1970-1990 & positive effect of advertising \\
\hline Young (1993) & OECD 1970-1990 & mixed \\
\hline
\end{tabular}

*See Saffer $(1995,1996,1998)$ for additional information on these studies. 
Table 2

Definitions and Means of Variables

\begin{tabular}{|c|c|c|}
\hline Variable & Definition & Mean \\
\hline $\begin{array}{l}\text { Log Per Capita } \\
\text { Consumption of Pure } \\
\text { Alcohol }\end{array}$ & $\begin{array}{l}\text { Natural log of per capita consumption of pure alcohol in the form of } \\
\text { beer, wine, and spirits. (Mean of per capita consumption of pure } \\
\text { alcohol in liters }=9.048 \text { ) }\end{array}$ & 2.147 \\
\hline $\begin{array}{l}\text { Partial Alcohol } \\
\text { Advertising Bans }\end{array}$ & $\begin{array}{l}\text { Number of media banning spirits or banning beer and wine advertising. } \\
\text { One for each of the following: television beer \& wine ban, television } \\
\text { spirits ban, radio beer \& wine ban, radio spirits ban, print beer \& wine } \\
\text { ban, and print spirits ban. }\end{array}$ & 1.585 \\
\hline $\begin{array}{l}\text { Total Alcohol } \\
\text { Advertising Bans }\end{array}$ & $\begin{array}{l}\text { Number of media banning all alcohol advertising. One for each media: } \\
\text { television, radio, and print. }\end{array}$ & 0.531 \\
\hline Cigarette Advertising Bans & $\begin{array}{l}\text { Number of cigarette advertising bans in effect. One for each of the } \\
\text { following media: television, radio, print, movie, outdoor, sponsorship, } \\
\text { and point of purchase. }\end{array}$ & 2.543 \\
\hline Alcohol Price & $\begin{array}{l}\text { Real price of a liter of pure alcohol. Total expenditure on alcoholic } \\
\text { beverages divided by pure alcohol consumption in liters. The variable } \\
\text { was adjusted by dividing by the GDP deflator and converted to } 1990 \\
\text { U.S. dollars by dividing by the purchasing power parity. }\end{array}$ & 45.674 \\
\hline Real Income & $\begin{array}{l}\text { National income divided by GDP deflator and converted to } 1990 \\
\text { thousands of U.S. dollars by dividing by the purchasing power parity. }\end{array}$ & 16.094 \\
\hline Beer Production & Total production of beer in hectoliters per capita. & 0.900 \\
\hline Wine Production & Total production of wine in hectoliters per capita. & 0.314 \\
\hline Alcohol Culture & Beer and wine consumption as a fraction of total alcohol consumption. & 0.770 \\
\hline $\begin{array}{l}\text { Government Expenditure } \\
\text { Share }\end{array}$ & Total government expenditures as a percentage of GDP. & 17.435 \\
\hline $\begin{array}{l}\text { Public Health Expenditure } \\
\text { Share }\end{array}$ & $\begin{array}{l}\text { Public expenditure on health as a fraction of the total expenditure on } \\
\text { health. }\end{array}$ & 0.756 \\
\hline
\end{tabular}

Data are from 1970 to 1995 for the following 20 countries: Australia, Austria, Belgium, Canada, Denmark, Finland, France, Germany, Ireland, Italy, Japan, Luxembourg, Netherlands, New Zealand, Norway, Portugal, Spain, Sweden, the United Kingdom, and the United States. 
Table 3

TSLS Regression Results

Alcohol Consumption

\begin{tabular}{|c|c|c|c|c|c|c|}
\hline Model & 1 & 2 & 3 & 4 & 5 & 6 \\
\hline Dependent Variable & $\begin{array}{c}\text { Alcohol } \\
\text { Consumption * }\end{array}$ & $\begin{array}{c}\text { Alcohol } \\
\text { Consumption } \\
\end{array}$ & $\begin{array}{c}\text { Partial Alcohol } \\
\text { Advertising Bans }\end{array}$ & $\begin{array}{c}\text { Alcohol } \\
\text { Consumption * }\end{array}$ & $\begin{array}{c}\text { Alcohol } \\
\text { Consumption }\end{array}$ & $\begin{array}{c}\text { Total Alcohol } \\
\text { Advertising Bans }\end{array}$ \\
\hline Alcohol Consumption & - & - & $\begin{array}{c}2.1361 \\
(1.30)\end{array}$ & - & - & $\begin{array}{l}1.4888 \\
(1.97)\end{array}$ \\
\hline $\begin{array}{l}\text { Partial Alcohol } \\
\text { Advertising Bans }\end{array}$ & $\begin{array}{c}-0.0486 \\
(-1.77) \\
\end{array}$ & $\begin{array}{l}0.0367 \\
(1.30) \\
\end{array}$ & - & - & - & - \\
\hline $\begin{array}{l}\text { Total Alcohol } \\
\text { Advertising Bans }\end{array}$ & - & - & - & $\begin{array}{c}-0.0898 \\
(-1.73) \\
\end{array}$ & $\begin{array}{r}0.0367 \\
(0.61) \\
\end{array}$ & - \\
\hline Alcohol Price & $\begin{array}{l}-0.0041 \\
(-5.17) \\
\end{array}$ & $\begin{array}{c}-0.0026 \\
(-2.18) \\
\end{array}$ & - & $\begin{array}{c}-0.0041 \\
(-5.42)\end{array}$ & $\begin{array}{l}-0.0025 \\
(-1.98)\end{array}$ & - \\
\hline Real Income & $\begin{array}{c}0.0151 \\
(3.37) \\
\end{array}$ & $\begin{array}{l}0.0186 \\
(2.85) \\
\end{array}$ & - & $\begin{array}{c}0.0156 \\
(3.81) \\
\end{array}$ & $\begin{array}{c}0.0181 \\
(2.61) \\
\end{array}$ & - \\
\hline Alcohol Culture & $\begin{array}{l}1.4378 \\
(5.22) \\
\end{array}$ & $\begin{array}{c}-0.2315 \\
(-0.55) \\
\end{array}$ & $\begin{array}{c}3.3018 \\
(1.06) \\
\end{array}$ & $\begin{array}{l}1.5731 \\
(5.08) \\
\end{array}$ & $\begin{array}{c}-0.1910 \\
(-0.45) \\
\end{array}$ & $\begin{array}{c}2.7331 \\
(1.78) \\
\end{array}$ \\
\hline Cigarette Advertising Bans & - & - & $\begin{array}{c}0.2954 \\
(1.60) \\
\end{array}$ & - & - & $\begin{array}{c}0.1715 \\
(1.93) \\
\end{array}$ \\
\hline Beer Production & - & - & $\begin{array}{c}0.2291 \\
(0.23) \\
\end{array}$ & - & - & $\begin{array}{l}-0.2479 \\
(-0.49) \\
\end{array}$ \\
\hline Wine Production & - & - & $\begin{array}{c}0.4054 \\
(1.55) \\
\end{array}$ & - & - & $\begin{array}{c}0.0919 \\
(0.75) \\
\end{array}$ \\
\hline Government Exp. Share & - & - & $\begin{array}{l}0.1358 \\
(2.26) \\
\end{array}$ & - & - & $\begin{array}{c}0.0520 \\
(2.24) \\
\end{array}$ \\
\hline Public Health Exp. Share & - & - & $\begin{array}{l}1.0668 \\
(0.37) \\
\end{array}$ & - & - & $\begin{array}{c}0.6244 \\
(0.50) \\
\end{array}$ \\
\hline Constant & $\begin{array}{l}1.0109 \\
(5.08) \\
\end{array}$ & $\begin{array}{l}1.4316 \\
(5.05) \\
\end{array}$ & $\begin{array}{c}-4.8473 \\
(-0.79) \\
\end{array}$ & $\begin{array}{c}0.8667 \\
(4.17) \\
\end{array}$ & $\begin{array}{l}1.5065 \\
(5.34) \\
\end{array}$ & $\begin{array}{c}-3.4340 \\
(-1.42) \\
\end{array}$ \\
\hline R-Square & 0.688 & 0.946 & 0.856 & 0.697 & 0.946 & 0.861 \\
\hline Number of Observations & 431 & 431 & 431 & 431 & 431 & 431 \\
\hline
\end{tabular}

Note: The alcohol consumption variable is logarithmic. Asymptotic t-statistics are in parentheses. The t-statistics are calculated using Huber standard errors. Country and time dummies are included except where noted. Data are from 1970 to 1995 for the following 20 countries: Australia, Austria, Belgium, Canada, Denmark, Finland, France, Germany, Ireland, Italy, Japan, Luxembourg, Netherlands, New Zealand, Norway, Portugal, Spain, Sweden, the United Kingdom, and the United States. * The structural equation excludes country dummies. 